\title{
La nueva izquierda latinoamericana frente a los medios de comunicación: una relación compleja
}

\section{Latin American new left facing mass media: a complex relationship \\ José Natanson}

José Natanson es periodista y politólogo, jefe de redacción de la revista Nueva Sociedad, Argentina. E- mail: jnatanson@nuso.org

\section{resumen}

Los gobiernos de la "nueva izquierda" que hoy ejercen el poder en buena parte de los países latinoamericanos libran batallas cotidianas contra los medios. El quiebre del sistema de partidos en algunos países, como Venezuela, Bolivia o Ecuador, abrió un espacio que fue ocupado por la prensa, que en algunos casos lideró a las fuerzas opositoras. Pero incluso en aquellos países en donde el tránsito al pos-neoliberalismo fue más gradual y sereno hay conflictos entre el gobierno y los medios. Esto se verifica en la decisión de muchos presidentes de crear un "by pass mediático" que les permita comunicarse directamente con la sociedad, el impulso a leyes regulatorias y la ampliación del complejo de medios públicos. Y, como telón de fondo, el hecho de que, por primera vez en décadas, el cuestionamiento a las instituciones de la democracia afecta también a los medios de comunicación.

\section{summary}

The "new left" governments in most Latin American countries have permanent battles against the media. Problems in the party systems in many of them (Venezuela, Bolivia or Ecuador) open a space quickly filled up by the media and, in same cases, the opposition take part in this action. But even in these countries which had a gradual pass to post-neoliberalism, there are conflicts between governments and the media. For that reason, some presidents create a "by pass mediático" which allows them to communicate with the people or send a bill to Congress to discuss these questions. The background of this situation is that this time is the first one in many decades that questions to democratic institutions have already affected to the media.

\section{palabras clave}

medios de comunicación / nueva izquierda / América latina / democracia

\section{keywords}

mass media / new left / Latin America / democracy 


\section{Introducción}

Entre todos los cambios que viene registrando la política, uno de los más notables es el proceso de desafección, en el sentido de una mayor distancia, a menudo teñida de desilusión, escepticismo y bronca, entre representantes y representados, acompañada por un debilitamiento de las tradiciones partidarias clásicas: ser peronista o radical en Argentina, o adeco o copeyano en Venezuela, o liberal o conservador en Colombia, ya no significa lo mismo que en el pasado. Con los partidos desestructurados, a veces astillados en mil pedazos incomprensibles, la política se asemeja a un proceso fluido, sin marcos y difícil de decodificar.

Esta tendencia -que, insisto, es global- se ha verificado de manera extrema en algunos países de América latina. Entre mediados del siglo pasado y principios del actual, varios países de la región vivieron crisis económicas que marcaron el final del ciclo neoliberal en medio de estallidos sociales y represiones con distintos grados de violencia. El tránsito del neoliberalismo a la "nueva izquierda" se procesó de manera más o menos constitucional, pero dejó sus secuelas. Fue así como sistemas partidarios que venían funcionando desde hacía años, a veces décadas, volaron por los aires: es el caso del Punto Fijo venezolano, de la "democracia pactada" boliviana y del sistema ecuatoriano, que en poco tiempo, a veces en cuestión de meses, dejaron de existir.

En estos países, el sistema político se recompuso a partir de la emergencia de liderazgos de alta popularidad (Chávez, Evo, Correa, Kirchner), que supieron reconstruir la autoridad presidencial y se propusieron un amplio programa de reformas. Pero tal recomposición abarcó solo a una parte del sistema político, la oficialista, dejando a la oposición sumida en una maraña de enredos internos, rencillas personales y desorientación. Este vacío fue ocupado por otros actores, incluyendo, o comenzando por, los medios de comunicación, que en algunos países, y en ciertos momentos, asumieron la conducción política de la oposición (en algunos casos acompañados por otros poderes fácticos, como los gobiernos autonómicos en Bolivia o la burocracia petrolera en la Venezuela del 2002).

Bernardo Sorj (2010) lo explica bien en su libro Poder político y medios de comunicación: "En el contexto del debilitamiento de otros medios tradicionales de articulación de voces de la oposición en la región, en particular de los partidos y los sindicatos, los medios aparecen como los únicos factores capaces de articular críticas al poder público". Esto se vería reforzado por el hecho de que, como explica Fernando Ruiz (2010) en el mismo libro, el periodismo latinoamericano se encuentra más cerca del modelo de periodismo militante y políticamente comprometido originario de Europa Occidental que del modelo profesional y supuestamente neutral que prevalece en el mundo anglosajón.

Primera idea entonces: el clima de polarización y enfrentamiento entre el Estado y los medios es menos el resultado de los ánimos censuradores de los gobiernos de izquierda o del espíritu desestabilizador de la prensa que de las condiciones políticas que se viven en la actualidad.

Esto no implica ignorar los conflictos de intereses; por supuesto existen, sobre todo cuando los medios se encuentran imbricados en complejos económicos que 
incluyen al agro (en Argentina), las finanzas (en Ecuador) o los hidrocarburos (en Bolivia). Simplemente, se trata de poner en contexto estas nuevas tensiones. No es casual, en este sentido, que los países que no registraron estallidos sociales ni quiebres políticos, en donde el tránsito al pos-neoliberalismo se produjo de manera más serena y gradual, la tensión gobierno-medios no haya adquirido semejante intensidad. Es el caso de Chile, Brasil y Uruguay. Sin embargo, un repaso por varias experiencias latinoamericanas revela parecidos incluso con estas naciones.

\section{El poder de la imagen}

Conviene destacar un dato, que a menudo se soslaya. A pesar de que muchos de ellos llegaron al poder con los medios más importantes militando en contra, casi todos los presidentes latinoamericanos son presidentes ultra-mediáticos, en un doble sentido: deben parte de su ascenso al poder de los medios de comunicación y son muy conscientes del peso e influencia de la prensa en el juego político. El investigador colombiano Omar Rincón los llama "telepresidentes" o "políticoscelebrities".

El caso de Evo Morales es ilustrativo. Fundador de un movimiento indígena que expresa valores milenarios y rescata tradiciones precolombinas, el Presidente boliviano es también un líder moderno, un hombre de su tiempo, que conoce, y está dispuesto a utilizar, el poder de la imagen, como demuestra la cuidadosa puesta en escena que acompañó el anuncio de la medida más importante de su gestión. El 1 de mayo de 2006, sorpresivamente, Evo apareció en el campo gasífero más importante del país y, parado sobre un estrado, leyó por un altavoz los alcances del decreto de nacionalización de los hidrocarburos. Vestía la pechera y el casco amarillo de Yacimientos Petrolíferos Fiscales Bolivianos y estaba acompañado por tropas militares, algo totalmente innecesario desde el punto de vista militar pero que le dio a la medida un tono teatral que reforzó la imagen y amplificó su impacto.

El ejemplo revela una clara conciencia acerca del poder de la imagen y la voluntad de utilizarla a su favor, en un intento de imponer sus propios términos y evitar que sean los medios quienes establezcan sus tiempos y sus formatos. Varios presidentes de la región, incluyendo a Lula, Kirchner y Evo, se resisten a conceder conferencias de prensa, y rara vez aceptan entrevistas. Prefieren evitar las mediaciones -en una táctica que el periodista boliviano Fernando Molina define adecuadamente como "by-pass mediático"- comunicándose directamente con la sociedad.

El uso y abuso de las cadenas oficiales es una muestra de ello: en Ecuador hubo 233 cadenas obligatorias hasta 2009, que se suman a los "enlaces de los sábados", espacios en los que el Presidente y los Ministros explican su gestión en la radio y la TV públicas, a las que los medios privados pueden engancharse voluntariamente (160 hasta 2010). Lo mismo hace Evo cuando transmite directamente un discurso desde un pueblo perdido del Atiplano, o los Kirchner cuando anuncian las medidas más importantes por cadena nacional. Pero el campeón es sin dudas Chávez: desde su asunción, el 2 de febrero de 1999, hasta el 22 de enero de 2010, 
Chávez se encadenó 1.995 veces, por un tiempo total de 1.310 horas y 36 minutos, según los datos de la consultora AGB.

Esto se complementa con la decisión de potenciar y ampliar el complejo de medios públicos, que revela la voluntad de avanzar en una mayor intervención del Estado, tal como se comprueba en otras dimensiones de la política y la economía, como la nacionalización de empresas en Venezuela, Bolivia, Ecuador y Argentina; la potenciación de empresas y bancos públicos, como el BNDES y Petrobrás, en Brasil; la creación de nuevos impuestos, como sucedió en Uruguay bajo el gobierno del Frente Amplio; y la extensión de los planes sociales, como sucede en casi toda la región. En un contexto de mayor presencia estatal en la vida política y económica de América latina, los gobiernos apuestan a fortalecer los medios públicos.

El hecho de que los mayores esfuerzos y recursos se hayan orientado a los medios audiovisuales confirma, una vez más, la clara conciencia acerca de su importancia e impacto, sobre todo en los sectores populares, que se informan básicamente a través de la televisión. El Gobierno venezolano cuenta hoy con seis canales de televisión: Venezolana de Televisión, Televisión Venezolana Social, que se difunde a través de la señal de RCTV, Avila TV, que antes pertenecía a la Alcaldía de Caracas, Asamblea Nacional Televisión, Vive TV y Telesur. En Ecuador, el Gobierno controla el periódico El Telégrafo, el canal Ecuador TV y la Radio Pública, a lo que se suma la creación de una agencia de noticias estatal. En Bolivia, al relanzamiento de Televisión Boliviana hay que añadir la transformación de Radio Illimani (hoy Patria Nueva) y la creación del diario Cambio. En algunos países, el Estado no multiplicó pero sí mejoró los medios existentes: es el caso de Canal 7 de Argentina y de Televisión Nacional de Uruguay, que la gestión frenteamplista modernizó mediante el simple método de limpiar las válvulas de las cámaras (lo que le quitó la turbidez característica a las transmisiones de la televisión pública).

Un aspecto a discutir es el del pluralismo. Aunque a menudo se proclama que se trata de medios estatales y no gubernamentales, y por más que se invoque el ejemplo de neutralidad política de la BBC, en general los gobiernos le han dado a sus medios un tono claramente oficialista, en algunos casos de un oficialismo exasperante. Quizás por ello los medios públicos han logrado en general una penetración limitada, en un esfuerzo que apunta a predicar a los ya conversos antes que a conquistar nuevas voluntades. En Venezuela, por ejemplo, las seis señales estatales apenas acumulan el 3 por ciento del total de la audiencia. En este marco, el Fútbol para Todos argentino no solo implica la posibilidad de mirar gratis los partidos, sino que contribuye a potenciar el total de la programación de Canal 7 y elevar su rating global.

Y, junto a la mejora de los medios estatales, existen otras herramientas, más discutibles pero más sutiles, a través de las cuales los gobiernos inciden en los contenidos de los medios privados. Me refiero a la potestad del Estado de prorrogar las licencias y al uso discrecional de la publicidad oficial. Esto es especialmente cierto en países pequeños, con mercados de publicidad privada reducidos, donde el Estado es el primer anunciador, por lo que los medios necesitan su apoyo para 
sobrevivir. Un buen ejemplo es Nicaragua, donde la utilización de esta herramienta por parte del gobierno sandinista permitió crear un poderoso entramado mediático para-estatal.

\section{EI debate sobre las leyes regulatorias}

La batalla entre el Estado y los medios ha asumido, en algunos casos, forma legal, a través de la propuesta o sanción de leyes tendientes a regular la actividad mediática. Se trata de un tema complejo que conviene estudiar caso por caso y cuyo análisis en profundidad excede las posibilidades de este espacio. Sin embargo, es posible apuntar algunas primeras conclusiones.

En general, la reacción ante estas iniciativas adquiere la forma de un reflejo corporativo que asume como un atentado a la libertad de expresión cualquier intento por regular las telecomunicaciones o la prensa. Pero no necesariamente debería ser así. Existen, por ejemplo, razonables regulaciones de mercado, que apuntan a evitar las posiciones monopólicas o dominantes. Esto sucede incluso en países muy celosos de la libertad de empresa y las garantías individuales como Estados Unidos, donde las normas establecen límites a la propiedad cruzada de licencias de TV, radio y cable, fijan cuotas máximas de mercado y limitan la posibilidad de que una misma empresa controle medios gráficos y audiovisuales.

El proyecto ecuatoriano, por ejemplo, prohíbe que una compañía dueña de un banco sea también la propietaria de un medio, con el argumento de que la orientación editorial del segundo puede quedar atada a los intereses del primero. La ley de medios argentina, aprobada en el Congreso tras un largo debate, apunta a desmonopolizar el panorama mediático estableciendo cuotas de mercado y prohibiendo el control de cierto número de licencias en la misma área geográfica. Algo similar podría ocurrir si el Congreso vota el proyecto oficial para declarar de "interés nacional" la producción de papel para diarios, lo que le permitiría a los editores acceder al insumo básico a un precio igualitario.

Pero el eje son siempre los medios audiovisuales. Las leyes y proyectos aprobados o en debate establecen una distribución equitativa de las frecuencias entre el Estado, el sector privado y el sector comunitario o de la sociedad civil (es el caso de Argentina y Ecuador y también de los proyectos que se discuten en Bolivia y Uruguay), fijan cuotas de producción nacional (Argentina, Ecuador, Venezuela) y establecen horarios y pautas para la protección de los niños (todas).

El tema se torna más complejo al analizar los procedimientos sancionatorios, en particular cuando éstos contemplan la suspensión -temporal o definitiva- de las licencias. El caso extremo es Venezuela. En mayo de 2007, fortalecido tras arrasar en la campaña por su reelección, Chávez decidió no renovar la licencia de RCTV, el canal más antiguo del país, con el argumento de que había apoyado el fallido golpe de Estado de 2002. La licencia estaba vencida y el Estado tenía la posibilidad de no renovarla. Por otra parte, el canal siguió transmitiendo por cable.

El trámite, sin embargo, fue irregular. Desde el punto de vista jurídico, si había una responsabilidad debía recaer sobre personas naturales -los dueños del canaly no sobre la empresa. Desde el punto de vista político, la intencionalidad está 
clara: el resto de los canales también habían acompañado la intentona golpista, pese a lo cual el Gobierno les permitió seguir operando, básicamente porque, finalmente convencidos de que había Chávez para rato, decidieron suavizar su línea editorial. El hecho de que Chávez haya formulado el anuncio de RCTV en un establecimiento militar y vestido de uniforme no ayudó a tranquilizar los ánimos. La OEA protestó, y el Presidente respondió tildando de "insulso" a su titular, José Miguel Insulza.

La decisión se suma al cierre de 32 radios primero y otras 29 después, con el argumento de que no cumplían con los requisitos legales para operar, y a las 40 causas -entre las iniciadas por funcionarios del Gobierno y las presentadas por particulares- contra el único canal claramente anti-chavista, Globovisión. Los motivos son variados: durante una entrevista con el director de RCTV, Globovisión difundió imágenes del atentado contra el Papa Juan Pablo II con la canción de Rubén Blades "Eso no termina aquí" de fondo. El Gobierno acusó a la emisora de incitar subliminalmente al magnicidio. En otra oportunidad, el canal fue denunciado por poner al aire un mensaje de texto de un televidente convocando a un golpe de Estado. En las últimas elecciones, Globovisión recibió otra denuncia por transmitir la reacción de un candidato a la gobernación de Carabobo que instó a tomar las oficinas del Consejo Nacional Electoral disconforme con el resultado.

Estos procedimientos sancionatorios se encuadran en la Ley de Responsabilidad Social en Radio y Televisión (conocida como Ley Resorte). Aprobada en diciembre de 2004, la norma prevé sanciones, que pueden llegar a la suspensión por 72 horas continuas de la señal, para "aquellos medios que difundan mensajes que promuevan o hagan apología o inciten a la guerra o a la alteración del orden público". Hay que señalar, además, la decisión -de la justicia, no del Gobierno, aunque obviamente hay sospechas sobre la influencia de éste sobre aquélla- de detener al dueño de Globovisión por una causa judicial que, aunque aparentemente no tendría vinculación con su actividad periodística, marca una coincidencia que es llamativa. Y el fallo - de la justicia, no del Gobierno- prohibiendo al diario El Nacional difundir imágenes de los muertos en una morgue de Caracas con el argumento de que "vulneran la integridad psíquica y moral de los niños, niñas o adolescentes".

El tema es complejo, pues alcanza con revisar rápidamente los portales antichavistas, que difunden abiertamente opiniones en algunos casos golpistas, racistas e injuriosas, para confirmar que la libertad de expresión sigue viva. Venezuela no es Cuba. Y el Gobierno no es el único actor en este juego peligroso: los medios venezolanos, en especial la televisión, lideraron el intento de golpe de Estado de 2004 y luego siguieron ubicándose, por momentos, en posiciones claramente desestabilizadoras. En todo caso, Venezuela se sitúa en un lugar particular, diferente al de Argentina o Bolivia, donde las leyes no regulan contenidos, el Estado no ha decretado la suspensión de ninguna licencia, no se ha aplicado la censura ni política ni judicial y no existen casos de periodistas presos. 


\section{Palabras finales}

Los datos del Latinobarómetro 2009 confirman que los medios de comunicación se encuentran a la cabeza de los ranking de confianza en diversas instituciones, superados solo por la Iglesia, y muy por arriba del gobierno, la empresa privada, la policía o los sindicatos. Sin embargo, la confrontación, en algunos países muy directa, con presidentes que gozan de una altísima popularidad ha contribuido a ponerlos en cuestión por primera vez desde el inicio de la última ola de democracia en América latina. La reacción destemplada de muchos de ellos ha contribuido a romper contratos de lectura basados en una supuesta aunque imposible neutralidad o independencia.

Los medios, cada vez más centrales, también son más discutidos. Existe hoy una conciencia cada vez más amplia en cuanto al verdadero lugar de los medios en la democracia: no solo una arena sino también un actor en el debate político. En su famoso libro La democracia y los partidos políticos, el sociólogo ruso Moisei Ostrogorski afirmó: "La función de las masas en una democracia no es gobernar sino intimidar a los gobernantes". En tiempos de globalización y auge de las nuevas tecnologías no solo gobiernan los políticos, sino también, en algún sentido, los medios. La novedad es que la sociedad ha comenzado a intimidarlos.

\section{Bibliografía}

M. OSTROGORSKI (2008) [1912], La democracia y los partidos políticos, Madrid, Trotta.

F. RUIZ (2010), "Fronteras móviles: caos y control en la relación entre medios y políticos en América Latina", en B. SORJ (Comp.), Poder político y medios de comunicación, Buenos Aires, Siglo XXI Editores - Plataforma Democrática.

B. SORJ (Comp.) (2010), Poder político y medios de comunicación, Buenos Aires, Siglo XXI Editores - Plataforma Democrática.

Recibido: 15/07/2010. Aceptado: 05/08/2010.

José Natanson, “La nueva izquierda latinoamericana frente a los medios de comunicación: una relación compleja". Revista Temas y Debates. ISSN 1666-0714, año 14, número 20, octubre 2010, pp 61-67. 